\begin{tabular}{|c|l|}
\hline Title & $\begin{array}{l}\text { Photocatalytic redox-combined synthesis of L-pipecolinic acid from L-lysine by suspended titania particles : effect of } \\
\text { noble metal loading on the selectivity and optical purity of the product }\end{array}$ \\
\hline Author(s) & Pal, Bonamali; Ikeda, Shigeru; Kominami, Hiroshi; Kera, Y oshiya; Ohtani, Bunsho \\
\hline Citation & $\begin{array}{l}\text { Journal of Catalysis, 217(1), 152-159 } \\
\text { https://doi.org/10.1016/S0021-9517(03)00049-6 }\end{array}$ \\
\hline Issue Date & $2003-07-01$ \\
\hline Doc URL & http://hdl.handle.net/2115/14649 \\
\hline Type & article (author version) \\
\hline File Information & JC2003-217-1.pdf \\
\hline
\end{tabular}

Instructions for use 
submitted to J. Catal.

Proofs to:

Professor Bunsho Ohtani

Catalysis Research Center, Hokkaido University, Sapporo 060-0811, JAPAN

facsimile: +81-11-706-4925

e-mail: ohtani@cat.hokudai.ac.jp

running title: Photocatalytic Synthesis of L-Pipecolinic Acid

\section{Photocatalytic Redox-Combined Synthesis of L-Pipecolinic Acid from L-Lysine by Suspended Titania Particles: Effect of Noble Metal Loading on the Selectivity and Optical Purity of the Product}

Bonamali Pal, ${ }^{\text {a }}$ Shigeru Ikeda, ${ }^{\text {a }}$ Hiroshi Kominami, ${ }^{\text {b }}$ Yoshiya Kera, ${ }^{b}$ and Bunsho Ohtani ${ }^{\text {a* }}$

${ }^{a}$ Catalysis Research Center, Hokkaido University, Sapporo 060-0811, Japan

${ }^{b}$ Faculty of Science and Engineering, Kinki University, Kowakae 3-4-1, Higashiosaka, Osaka 577, Japan

Received October XX, 2002

*To whom correspondence should be addressed. Fax: +81-11-706-4925. E-mail:

ohtani@cat.hokudai.ac.jp 
Photocatalytic (> $300 \mathrm{~nm}$ ) conversion of L-(S)-lysine (L-Lys), in its neutralized aqueous solution, into L-pipecolinic acid (L-PCA) under deaerated conditions at $298 \mathrm{~K}$ was investigated in detail using suspended $\mathrm{TiO}_{2}$ powders (Degussa P-25, Ishihara ST-01, and HyCOM TiO 2 ) loaded with platinum $(\mathrm{Pt})$, rhodium $(\mathrm{Rh})$, or palladium $(\mathrm{Pd})$. A common feature of the results of experiments using a wide variety of metal-loaded $\mathrm{TiO}_{2}$ photocatalysts is that the rate of PCA formation ( $\left.\mathrm{r}_{\mathrm{PCA}}\right)$ was greatly reduced when higher optical purity of PCA ( $\left.\mathrm{OP}_{\mathrm{PCA}}\right)$, i.e., enantio excess of the L-isomer of PCA, was obtained; higher r $\mathrm{rCA}_{\mathrm{PC}}$ was achieved by the use of Pt-loaded $\mathrm{TiO}_{2}$

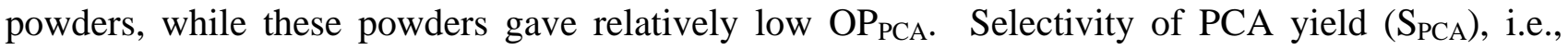
amount of PCA production based on L-Lys consumption, also tended to increase with decrease in OP $P_{\text {PCA }}$, giving a master curve in the plots of $\mathrm{OP}_{\mathrm{PCA}}$ versus $\mathrm{S}_{\mathrm{PCA}}$. Among the $\mathrm{TiO}_{2}$ powders used in this study, HyCOM $\mathrm{TiO}_{2}$ showed relatively high $\mathrm{OP}_{\mathrm{PCA}}$ and $\mathrm{S}_{\mathrm{PCA}}$ but not optimum $\mathrm{S}_{\mathrm{PCA}}$ and $\mathrm{OP}_{\mathrm{PCA}}$ simultaneously. In order to interpret such relations, the mechanism of stereoselective synthesis of the L-isomer of PCA (L-PCA) was investigated using isotope-labeled $\alpha-{ }^{15} \mathrm{~N}$-L-lysine with quantitative analysis of incorporation of ${ }^{15} \mathrm{~N}$ in PCA and ammonia $\left(\mathrm{NH}_{3}\right)$, a by-product. It was observed for several photocatalysts that the ${ }^{15} \mathrm{~N}$ proportion $\left(\mathrm{P}_{15}\right)$ in PCA was almost equal to OP $\mathrm{PCA}_{\text {, }}$ suggesting that oxidative cleavage by photogenerated positive holes of the $\varepsilon$-amino moiety of L-Lys gave optically pure L-PCA through retention of chirality at the $\alpha$-carbon in the presumed intermediate, a cyclic Schiff base ( $\alpha$-CSB), which undergoes reduction by photoexcited electrons into PCA. From $\mathrm{P}_{15}$ in $\mathrm{NH}_{3}$ and PCA, the selectivity of oxidation between $\alpha$ and $\varepsilon$-amino groups in L-Lys by photoexcited positive holes $\left(\mathrm{h}^{+}\right)$and the efficiency of reduction of $\alpha$-CSB (produced via $\varepsilon$ amino group oxidation to give optically pure PCA) and $\varepsilon$-CSB (produced via $\alpha$-amino group oxidation to give racemic PCA) by photoexcited electrons ( $\left.\mathrm{e}^{-}\right)$were calculated. The former was found to be independent of the kind of photocatalyst, especially the loaded metal, while the latter was influenced markedly only by the loaded metal. It was clarified that $\mathrm{OP}_{\mathrm{PCA}}$ and $\mathrm{S}_{\mathrm{PCA}}$ obtained for various $\mathrm{TiO}_{2}$ powders used in the present study were strongly governed by the reduction stage, i.e., the efficiency of reduction of two types of CSB. When S SCA was relatively low, photocatalysts, favoring the reduction of $\alpha$-CSB rather than $\varepsilon$-CSB, gave higher $\mathrm{OP}_{\mathrm{PCA}}$ but lower $\mathrm{S}_{\mathrm{PCA}}$, since some 
$\varepsilon$-CSB remained unreduced to give racemic PCA. In contrast, at higher $\mathrm{S}_{\mathrm{PCA}}$, both CSB's were reduced non-selectively and $\mathrm{OP}_{\mathrm{PCA}}$ was found to be determined mainly by the selectivity in the oxidation stage. The relatively low yield of molecular hydrogen $\left(\mathrm{H}_{2}\right)$ when higher $\mathrm{S}_{\mathrm{PCA}}$ was achieved is consistent with the mechanism in which $\mathrm{H}_{2}$ liberation occurs instead of the reduction of CSB's by $\mathrm{e}^{-}$. Thus, the general tendency of plots between $\mathrm{OP}_{\mathrm{PCA}}$ and $\mathrm{S}_{\mathrm{PCA}}$ could be explained by the above-described redox-combined mechanism of photocatalysis.

Key Words: photocatalysis; redex-combined mechanism; metal-loaded titania particles; Llysine; L-pipecolinic acid; Schiff-base intermediate.

\section{INTRODUCTION}

Pipecolinic acid (PCA) is one of the most important intermediate compounds for the syntheses of a wide range of medicines and/or biologically active chemical compounds; ${ }^{1}$ for example, a commercially available local anesthetic, L-N-propylpipecolinic acid 2,6-xylidide, is synthesized from L-(S)-PCA (L-PCA). ${ }^{2}$ In order to obtain optically active L-PCA, deaminocyclization of L-(S)-lysine (L-Lys) is a preferable green chemistry process, because the optically pure, but cheap, starting material is readily available and only ammonia is liberated as a byproduct in the reaction stoichiometry. Several routes of stoichiometric production of L-PCA from L-

Lys have been reported, ${ }^{3-5}$ but they are non-catalytic and multi-step routes. In 1990, we reported a one-step photocatalytic synthesis of L-PCA by photoirradiation of a deaerated aqueous solution of L-Lys with suspended particulate semiconductor photocatalysts, such as titanium(IV) oxide $\left(\mathrm{TiO}_{2}\right)$ or cadmium(II) sulfide (CdS). ${ }^{6,7}$ This photocatalytic synthesis proceeds under atmospheric pressure at room temperature and needs no protection of the functional groups in L-Lys. To the best of our knowledge, this is a unique example of catalytic one-step synthesis of L-PCA from L-Lys and a greener process compared with the conventional synthetic methods. 
Photocatalysis is a redox reaction driven by photoexcited electrons $\left(\mathrm{e}^{-}\right.$) in the conduction band and simultaneously generated positive holes $\left(\mathrm{h}^{+}\right)$in the valence band of semiconducting materials when photoirradiated with the light of energy greater than the band gap between the valence and conduction bands., 8,9 Generally speaking, in the presence of molecular oxygen $\left(\mathrm{O}_{2}\right)$ under ordinary atmospheric conditions, the target of reduction by $\mathrm{e}^{-}$is limited to $\mathrm{O}_{2}$ and the proposed resulting products, superoxide anion, ${ }^{10}$ hydroperoxy $^{11}$ and/or hydroxyl ${ }^{12}$ radicals, are all oxidants. Therefore, the photocatalytic reaction under aerated conditions is oxidation of substrates by both $\mathrm{h}^{+}$ and the oxidants derived from $\mathrm{e}^{-}$, and this is one of the main reasons for the potential environmental applications of photocatalysis, i.e., complete oxidation and mineralization of organic pollutants in air and/or water. ${ }^{13,14}$ In order to apply this photocatalytic oxidation to organic synthesis, it is necessary to avoid over-oxidation (mineralization) of substrates; several examples of photocatalytic oxidative conversion of organic substrates have been reported. ${ }^{15-18}$ On the other hand, when the photocatalytic reactions are carried out under deaerated conditions, both reduction and oxidation by $\mathrm{e}^{-}$and $\mathrm{h}^{+}$, respectively, can be utilized for conversion of organic substrates; for example, transfer hydrogenation of nitrogen-containing compounds along with the oxidation of alcohols ${ }^{19-21}$ has been reported. Similar to the reported photocatalytic cyclization of $\alpha, \omega$-diamines, ${ }^{22}$ the proposed mechanism of the above-mentioned photocatalytic deaminocyclization of L-Lys involves successive oxidation of one of the amino groups in L-Lys into imines by $\mathrm{h}^{+}$, hydrolysis of the imines into aldehyde or ketone, condensation of them with the remaining amino group into a cyclic Schiff base (CSB), and reduction of CSB into PCA by $\mathrm{e}^{-6},{ }^{6}$ as shown in Scheme 1 . Such combination of reduction and oxidation is one of the characteristic features of photocatalytic PCA synthesis, since, equimolar oxidation and reduction by positive holes and electrons, respectively, proceed separately in the ordinary photocatalytic reaction systems, giving different reduction and oxidation products. Since $\mathrm{h}^{+}$and $\mathrm{e}^{-}$produced in a particle must be consumed on the surface of each particle in the photocatalytic reaction by semiconductor particles, the sites for oxidation and reduction might be located nearby, enabling induction of a redox-combined reaction. Several examples of such redoxcombined photocatalytic reactions have been reported. ${ }^{23-29}$ 
Optical purity of the product PCA (OP $\left.\mathrm{PCA}_{\mathrm{N}}\right)$ was found to depend on the kind of photocatalyst; $\mathrm{TiO}_{2}$ and CdS-based particulate photocatalysts gave L-excess and almost racemic PCA, respectively. ${ }^{6}$ This dependence of $\mathrm{OP}_{\mathrm{PCA}}$ has been attributed to the difference in the position, i.e., which amino group in L-Lys undergoes preferential oxidative attack by $\mathrm{h}^{+}$; as shown in Scheme 1 , oxidation of an $\alpha$-amino group into $\alpha$-keto acid leads to the loss of chirality, whereas oxidation of an $\varepsilon$-amino group has no effect on the optical activity. Infrared spectroscopic analyses of the behavior of L-Lys adsorbed on thin film photocatalysts suggested that $\mathrm{h}^{+}$in $\mathrm{CdS}$ can oxidize only the $\alpha$-amino group, while $\mathrm{TiO}_{2}$ oxidizes the $\varepsilon$-amino group predominantly. ${ }^{30}$ Therefore, in order to achieve high $\mathrm{OP}_{\mathrm{PCA}}$ in the photocatalytic synthesis of PCA from L-Lys, the use of a $\mathrm{TiO}_{2}$-based photocatalyst is preferable, though we have not been able to obtain optically pure PCA by $\mathrm{TiO}_{2}$ photocatalysis due to the partial contribution of the $\alpha$-amino group oxidation route, and further regulation is therefore needed for application of this photocatalytic process to practical organic synthesis.

The above results lead to a strategy for producing optically active PCA through the preferential oxidation of an $\varepsilon$-amino group in L-Lys by changing the surface physicochemical properties of the catalysts with the loading of co-catalysts. In this paper, we describe the results of a study on the effects of various $\mathrm{TiO}_{2}$ powders and co-catalysts on photocatalytic PCA synthesis. We have attempted to provide an overview for the correlation and improvement of $\mathrm{OP}_{\mathrm{PCA}}$, selectivity for PCA production, and PCA yield of the above-mentioned reaction systems with focus on the reaction mechanism, which was investigated by measurement of isotopic distributions of nitrogen $\left({ }^{14} \mathrm{~N}\right.$ and $\left.{ }^{15} \mathrm{~N}\right)$ in $\mathrm{NH}_{3}$ and PCA using $\alpha-{ }^{15} \mathrm{~N}-\mathrm{L}$-lysine $\left(\alpha-{ }^{15} \mathrm{~N}-\mathrm{L}-\mathrm{lys}\right)$ as a starting material.

\section{EXPERIMENTALS AND METHODS}

\section{Materials}

Commercial $\mathrm{TiO}_{2}$ samples, Degussa P-25 (ca. $50 \mathrm{~m}^{2} \mathrm{~g}^{-1}$, a mixture of anatase and rutile crystallites), Ishihara ST-01 (320 $\mathrm{m}^{2} \mathrm{~g}^{-1}$, mainly anatase), and synthesized HyCOM (ydrothermal Crystallization in Organic Media), ${ }^{31,32}$ which was calcined at $823 \mathrm{~K}$ for $1 \mathrm{~h}$ under air $\left(67 \mathrm{~m}^{2} \mathrm{~g}^{-1}\right.$, anatase), were used in this study. Metal salts such as chloroplatinic acid $\left(\mathrm{H}_{2} \mathrm{PtCl}_{6} \cdot 6 \mathrm{H}_{2} \mathrm{O}\right)$, 
palladium chloride $\left(\mathrm{PdCl}_{2}\right)$, and rhodium chloride $\left(\mathrm{RhCl}_{3}\right)$ (Wako Pure Chemicals) were used as received for the metal loading. L-Lys hydrochloride (Wako) and $\alpha-{ }^{15} \mathrm{~N}-\mathrm{L}-\mathrm{Lys}$ dihydrochloride (99\%, Cambridge Isotope Laboratories) were used in the photocatalytic reaction after neutralization by sodium hydroxide $(\mathrm{NaOH})$. Benzaldehyde, acetonitrile, and an amino acid derivatizing agent, BSTFA (N,O-bis(trimethylsilyl)trifluoroacetamide, GL Sciences), were used without further purification.

\section{Metal Loading}

Loading of noble metals onto the $\mathrm{TiO}_{2}$ powders was achieved by impregnation and subsequent $\mathrm{H}_{2}$ reduction as follows. To an aqueous suspension $\left(50-100 \mathrm{~cm}^{3}\right)$ a calculated amount of $\mathrm{TiO}_{2}$, a metal chloride solution (in most cases ca. $1 \mathrm{mmol} \mathrm{dm}{ }^{-3}$ ), was added dropwise for $1 \mathrm{~h}$ with magnetic stirring at room temperature. The mixture was gently stirred at ca. $353 \mathrm{~K}$, evaporated to dryness, and then further dried at $383 \mathrm{~K}$ overnight in an oven. The powder thus obtained was ground in a mortar to produce fine powder and placed in a quartz cylindrical vessel. The vessel was heated in an electric furnace up to $573 \mathrm{~K}$ with an argon (Ar) flow through a quartz tube inserted in the vessel and kept at this temperature for $15 \mathrm{~min}$. Then a flow of hydrogen $\left(\mathrm{H}_{2}\right)\left(40 \mathrm{~cm}^{3} \mathrm{~min}^{-1}\right)$ was introduced into the vessel with increase in temperature up to $773 \mathrm{~K}$, and the vessel was kept at this temperature for $3 \mathrm{~h}$. The vessel was inclined and rotated at ca. $70 \mathrm{rpm}$ throughout the reduction process to avoid heterogeneity. In all catalyst preparation procedures, the content of metal was $2 \%$, calculated as the weight ratio of loaded metal to $\mathrm{TiO}_{2}$.

\section{Photocatalytic Reaction and Product Analysis}

A metal-loaded catalyst $(50 \mathrm{mg})$ was suspended in an aqueous solution $\left(5.0 \mathrm{~cm}^{3}\right)$ containing L-Lys (100 $\mu \mathrm{mol})$ and photoirradiated by a high-pressure mercury arc (Eiko-sha, $400 \mathrm{~W})$ under Ar. The photoirradiation was performed through a cylindrical Pyrex glass filter and a glass reaction tube (18 $\mathrm{mm}$ in diameter and $180 \mathrm{~mm}$ in length) so that light of wavelength $>300 \mathrm{~nm}$ reached the suspension. The temperature of the suspension during photoirradiation was maintained at $298 \pm 0.5$ 
$\mathrm{K}$ by the use of a thermostated water bath. For a rough estimation of photonic efficiency of the photocatalytic reaction, incident photon flux (1500 $\mu \mathrm{mol} \mathrm{h}{ }^{-1}$ at a wavelength between 300 and 400 $\mathrm{nm}$ for the irradiated area of the reaction tube, $5.1 \mathrm{~cm}^{2}$ ) was estimated by total emission energy of the mercury arc at the sample position and a spectrum measured using a Molectron Power Max 5200 laser power meter and a Hamamatsu Photonics C7473-36 photonic multi-channel analyzer (resolution: $0.8 \mathrm{~nm}$ ), respectively.

After irradiation for $1 \mathrm{~h}$, a portion $\left(0.2 \mathrm{~cm}^{3}\right)$ of the gas phase of the sample was withdrawn with a syringe and subjected to gas chromatographic analysis (GC, Shimadzu GC-8A with an MS5A column (GL Sciences) and a TCD detector) of molecular hydrogen $\left(\mathrm{H}_{2}\right)$. The yield of enantiomers of PCA, as well as the amount of unreacted L-Lys, was measured by high-performance liquid chromatography (HPLC, Shimadzu LC-6A equipped with a Daicel ChiralPak MA(+) column and an ultraviolet absorption detector). These product analyses have been reported in detail elsewhere. $^{33,34}$

Derivatization of $\mathrm{NH}_{3}$, a by-product, into benzylamine (BA) was performed as follows. To 5 $\mathrm{cm}^{-3}$ of a reaction mixture containing products $\left(\mathrm{NH}_{3}\right.$ and PCA) and unreacted L-Lys (or $\alpha-{ }^{15} \mathrm{~N}-\mathrm{L}-\mathrm{lys}$ ) as well as a metal-loaded catalyst, neat benzaldehyde (1 mmol) was injected through a rubber septum. The suspension was vigorously stirred under Ar for $1 \mathrm{~h}$ and subsequently stirred under $\mathrm{H}_{2}$ for $1 \mathrm{~h}$. After acidification of the suspension with hydrochloric acid to convert benzylamine into its water-soluble hydrochloride salt, unreacted benzaldehyde was removed by extraction with diethyl ether. The aqueous layer was evaporated to dryness to yield a yellowish residue. A portion of the residue was again dissolved in water and was analyzed by HPLC with a Daicel Crownpak CR(+) column (for BA) or a Daicel ChiralPak MA(+) column (for PCA). GC-mass spectroscopy (MS) measurements were performed with a Shimadzu QP5050A equipped with a fused silica capillary (J\&W DB-1). A small amount of the yellowish residue was treated with BSTFA in acetonitrile in a sealed glass tube under Ar, heated at $423 \mathrm{~K}$ for $2.5 \mathrm{~h}$, and injected. MS patterns of fractions were recorded in chemical ionization (CI with isobutene) mode. 


\section{RESULTS AND DISCUSSION}

\section{Photocatalytic Activity of Metal-loaded $\mathrm{TiO}_{2}$ Powders}

Figure 1 shows rate of PCA formation ( $\left.\mathrm{r}_{\mathrm{PCA}}\right)$, optical purity of PCA ( $\left.\mathrm{OP}_{\mathrm{PCA}}\right)$, i.e., enantio excess percentage of the L-isomer of PCA, and selectivity of PCA yield ( $\left.\mathrm{S}_{\mathrm{PCA}}\right)$ based on L-Lys consumption for photocatalytic reaction of L-Lys in aqueous suspensions of various metal-loaded $\mathrm{TiO}_{2}$ powders. A preliminary experiment showed that $\mathrm{TiO}_{2}$ loaded with nickel, copper, or silver gave appreciable but very low photocatalytic activity for PCA production (data not shown), and noble metals, Pt, Pd and Rh, were used as representative co-catalysts in this study. All of the powders used in this study gave PCA from L-Lys, and a wide variety of photocatalytic activities was observed depending on the kind of $\mathrm{TiO}_{2}$ and the loaded metal. A common feature was that $\mathrm{r}_{\mathrm{PCA}}$ was greatly reduced when higher $\mathrm{OP}_{\mathrm{PCA}}$ and lower $\mathrm{S}_{\mathrm{PCA}}$ were obtained, e.g., Pd-loaded P-25 exhibited highest $\mathrm{OP}_{\mathrm{PCA}}$ but lowest $\mathrm{r}_{\mathrm{PCA}}$ and $\mathrm{S}_{\mathrm{PCA}}$. Similar photocatalytic activity, relatively high $\mathrm{OP}_{\mathrm{PCA}}$ but low $\mathrm{r}_{\mathrm{PCA}}$ and $\mathrm{S}_{\mathrm{PCA}}$, was observed for the other Pd-loaded samples. On the other hand, when any of the $\mathrm{TiO}_{2}$ powders were used, loading of Pt tended to induce high $\mathrm{r}_{\mathrm{PCA}}$ and $\mathrm{S}_{\mathrm{PCA}}$. The highest $\mathrm{r}_{\mathrm{PCA}}$ (ca. $80 \mu \mathrm{mol} \mathrm{h}^{-1}$ ) and relatively high $\mathrm{S}_{\mathrm{PCA}}$ (ca. 70\%) was achieved by the use of Pt-loaded HyCOM-TiO . This highest $\mathrm{r}_{\mathrm{PCA}}$ corresponded to photonic efficiency of $11 \%$ on the assumption of a two-electron process as discussed later. It is notable that almost complete consumption of L-Lys was achieved by 0.5-h irradiation of this photocatalyst, while other $\mathrm{TiO}_{2}$ powders required an hour or more of irradiation. However, with respect to $\mathrm{OP}_{\mathrm{PCA}}$, the photocatalytic performance of these Pt-loaded $\mathrm{TiO}_{2}$ powders was poor in comparison with that of other metal-loaded samples.

As described before, the present photocatalytic reaction has been proved to proceed via a combination of oxidation of L-Lys with positive holes $\left(\mathrm{h}^{+}\right)$and reduction of CSB intermediates with electrons (e), as shown in Scheme 1. It has been proposed that Pt loaded on photocatalysts captures $\mathrm{e}^{-}$and acts as a cathode for the reduction of protons or other reaction intermediates. ${ }^{33}$ In the case of $\mathrm{TiO}_{2}$, loaded Pt should work as a sole reduction site, because bare $\mathrm{TiO}_{2}$, without modification with Pt, has poor ability for reduction of adsorbed substrates except for suitable electron acceptors such as 
molecular oxygen. Actually, the photocatalytic activity of bare $\mathrm{TiO}_{2}$ powders in the present system was negligibly small (data not shown). Therefore, it is thought that the functions of other loaded metals such as Rh and Pd used in the present study are similar to that of Pt, a catalytic site not for the oxidation of L-Lys but for the reduction of CSB's by $\mathrm{e}^{-}$, and the observed dependence of photocatalytic performance on the kind of loaded metal is thought to be due to the difference in catalytic abilities of these metals for CSB reduction as is discussed later.

There was appreciable dependence of photocatalytic activity on the kind of $\mathrm{TiO}_{2}$ powder; the HyCOM $\mathrm{TiO}_{2}$ powders showed high $\mathrm{r}_{\mathrm{PCA}}$ when any kind of metal was loaded. For example, even when HyCOM $\mathrm{TiO}_{2}$ loaded with Rh, which reduced each rPCA of Pt-loaded HyCOM, P-25, and ST01 powders, was used, the $\mathrm{r}_{\mathrm{PCA}}$ was still higher than those of other $\mathrm{TiO}_{2}$ powders loaded with Pt. High photocatalytic activity of $\mathrm{HyCOM} \mathrm{TiO}_{2}$ powders, similar to that found in the present study, has been observed in various liquid-phase photocatalytic systems and might be due to well-balanced structural features of $\mathrm{HyCOM} \mathrm{TiO}_{2}$ powders; i.e., high crystallinity and large surface area, leading to lesser recombination between $\mathrm{e}^{-}$and $\mathrm{h}^{+}$and greater adsorption of substrates, respectively. 7,31,35 Detailed discussions on the correlation between photocatalytic activity and physicochemical properties of HyCOM $\mathrm{TiO}_{2}$ powders will be published elsewhere.

Figure 2 shows plots of $\mathrm{OP}_{\mathrm{PCA}}$ versus $\mathrm{S}_{\mathrm{PCA}}$ extracted from the three-dimensional plot of Fig. 1. There is a clear relation between them, i.e., $\mathrm{S}_{\mathrm{PCA}}$ increased with decrease in $\mathrm{OP}_{\mathrm{PCA}}$, which gave a master curve, though $\mathrm{HyCOM} \mathrm{TiO}_{2}$ powders tended to show slightly higher $\mathrm{S}_{\mathrm{PCA}}$ and $\mathrm{OP}_{\mathrm{PCA}}$ among the $\mathrm{TiO}_{2}$ samples used. These results suggest that achievement of optimum $\mathrm{S}_{\text {PCA }}$ and OP $\mathrm{PCA}$ simultaneously by each catalyst is difficult.

It can also be seen in Fig. 2 that both $\mathrm{S}_{\mathrm{PCA}}$ and $\mathrm{OP}_{\mathrm{PCA}}$ depend mainly on the kind of loaded metal. Among them, Pt loading tended to give higher $\mathrm{S}_{\mathrm{PCA}}$ but lower $\mathrm{OP}_{\mathrm{PCA}}$. This trend was reversed for Pd-loaded catalysts, while Rh loading gave moderate photocatalytic activity. Since loaded metals are thought to act as reduction sites, as mentioned above, these results also indicate that the difference in catalytic performances in the reduction stage has a significant influence on 
$\mathrm{S}_{\mathrm{PCA}}$ and $\mathrm{OP}_{\mathrm{PCA}}$. This relation of $\mathrm{S}_{\mathrm{PCA}}$ and $\mathrm{OP}_{\mathrm{PCA}}$ is discussed later on the basis of mechanistic findings.

Mechanistic Insights into Photocatalytic Reaction of L-Lys

As shown in Scheme 1, the overall process of photocatalytic production of PCA from L-Lys consists of three steps: oxidation of one of the amino groups of L-Lys with $\mathrm{h}^{+}$to yield imines, hydrolysis of imines into $\alpha$-keto acid and $\delta$-aldehyde along with the release of ammonia $\left(\mathrm{NH}_{3}\right)$ followed by intramolecular condensation between residual amino groups and the carbonyl group into two types of cyclic Schiff base (CSB) intermediates, and reduction of CSB's formally by $\mathrm{e}^{-}$along with addition of protons to yield the final product, PCA. Thus, observed $\mathrm{OP}_{\mathrm{PCA}}$ and $\mathrm{S}_{\mathrm{PCA}}$ must be governed by the selectivities of both oxidation (which amino group in L-Lys is oxidized) and reduction (efficiency in reduction of CSB's). In order to interpret the observed difference in photocatalytic performances of several metal-loaded $\mathrm{TiO}_{2}$ powders, the selectivity in each stage should be evaluated separately, and we have therefore tried to determine the isotopic distributions of nitrogen $\left({ }^{14} \mathrm{~N}\right.$ and $\left.{ }^{15} \mathrm{~N}\right)$ in $\mathrm{NH}_{3}$ (as a form of benzylamine, BA) and PCA using $\alpha-{ }^{15} \mathrm{~N}-\mathrm{L}$-lysine $(\alpha-$ $\left.{ }^{15} \mathrm{~N}-\mathrm{L}-\mathrm{Lys}\right)$ as a starting material.

Figure 3 shows parts of GC-MS patterns of PCA synthesized photocatalytically from L-Lys and $\alpha-{ }^{15} \mathrm{~N}$-L-Lys and those of BA prepared by post-irradiation condensation between $\mathrm{NH}_{3}$ and benzaldehyde followed by $\mathrm{H}_{2}$ reduction (Scheme 2). The data obtained using Pt-loaded P-25 are shown in this figure. Peaks at m/z 274 and $\mathrm{m} / \mathrm{z} 252$ are assigned to parent peaks $\left([\mathrm{M}+1]^{+}\right)$of bis(trimethylsilyl (TMS)) derivative of PCA and BA, respectively. It is clear by comparison of MS patterns of PCA and BA synthesized from $\alpha-{ }^{15} \mathrm{~N}-\mathrm{L}-\mathrm{L}$ ys with those from L-Lys that both products gave fragments of one atomic unit larger molecular weight together with standard fragments, indicating the incorporation of ${ }^{15} \mathrm{~N}$ atoms in PCA and BA molecules. Based on the assumption that the isotopic fractions (m/z $274: 275: 276=100: 24: 10$ for PCA and m/z $252: 253: 254=100:$ 29 : 10 for $\mathrm{BA}$ ) in samples obtained from L-Lys are also applicable to the ${ }^{15} \mathrm{~N}$-incorporated molecules, the isotopic distributions of photocatalytic products, defined as the proportion of the 
amount of ${ }^{15} \mathrm{~N}$-incorporated products in the total amount of products $\left(\mathrm{P}_{15} / \%\right)$, of PCA and $\mathrm{NH}_{3}$ on this photocatalyst were estimated to be 46 and 45 for PCA and $\mathrm{NH}_{3}$, respectively.

Table 1 summarizes $\mathrm{P}_{15}$ in PCA and $\mathrm{NH}_{3}, \mathrm{OP}_{\mathrm{PCA}}, \mathrm{S}_{\mathrm{PCA}}$, and amount of molecular hydrogen $\left(\mathrm{H}_{2}\right)$ production $\left(\mathrm{Y}_{\mathrm{H} 2} / \mu \mathrm{mol}\right)$. Based on the fact that $\mathrm{S}_{\mathrm{PCA}}, \mathrm{OP}_{\mathrm{PCA}}$, and $\mathrm{Y}_{\mathrm{H} 2}$ were not greatly affected by the source material, L-Lys and $\alpha-{ }^{15} \mathrm{~N}$-L-Lys, by a few representative photocatalysts, it was assumed that L-Lys and $\alpha-{ }^{15} \mathrm{~N}$-L-Lys behave similarly in the photocatalytic reaction. Mainly due to the relatively low yield of $\mathrm{NH}_{3}$ by some Pd- and Rh-loaded photocatalysts, leading to an insufficient amount of BA yield for GC-MS analysis, we could not detect any peak of BA to obtain $\mathrm{P}_{15}$. It was observed for several photocatalysts that $\mathrm{P}_{15}$ in PCA was comparable to $\mathrm{OP}_{\mathrm{PCA}}$, though a slight difference was observed on Pt-loaded P-25, indicating that oxidative cleavage by $\mathrm{h}^{+}$of an $\varepsilon$-amino moiety of L-Lys gave optically pure L-PCA through retention of chirality of the $\alpha$-carbon in the presumed intermediate of $\alpha$-CSB, which undergoes reduction by $\mathrm{e}^{-}$into L-PCA. On the other hand, $\mathrm{P}_{15}$ in $\mathrm{NH}_{3}$ reflects the proportion of oxidation at the $\alpha$-amino moiety in consumed L-Lys, since $\mathrm{NH}_{3}$ is produced via oxidation of L-Lys followed by hydrolysis of the imines. It is clear that $\mathrm{P}_{15}$ in $\mathrm{NH}_{3}$ was almost constant, i.e., independent of the kind of photocatalyst used in the present experiments. In our previous study, ${ }^{30}$ we showed that L-Lys is adsorbed on the $\mathrm{TiO}_{2}$ surface through protonation of an $\alpha$-amino group by acidic hydroxyl groups on the surface. Because a basic amino group undergoes oxidation more easily than does a protonated amino group such as an $\alpha$-amino group of Lys in its neutral aqueous solution, protonation on the $\mathrm{TiO}_{2}$ surface enhances the relative probability of oxidation of the $\varepsilon$-amino group to give optically active PCA. The constant $\mathrm{P}_{15}$ in $\mathrm{NH}_{3}$ observed in this study indicates that the surface properties of $\mathrm{TiO}_{2}$ samples are not so different and that the selectivity in the first oxidation step is less controllable by metal loading.

On the other hand, significant differences have been observed in $\mathrm{P}_{15}$ in PCA depending on the kind of photocatalyst, especially a loaded metal. These results suggest that the observed difference in $\mathrm{OP}_{\mathrm{PCA}}$ is due to the difference in efficiencies of reduction of two types of CSB, $\alpha$-CSB and $\varepsilon$-CSB, the former of which is produced via $\varepsilon$-amino group oxidation to give the L-isomer of PCA and the latter of which is produced via $\alpha$-amino group oxidation to give racemic PCA. 
For more precise interpretation of the observed trend of plots between $\mathrm{OP}_{\mathrm{PCA}}$ and $\mathrm{S}_{\mathrm{PCA}}$ as shown in Fig. 2, we tried to quantify the efficiency of reduction of two types of CSB by analyzing photocatalytic activity and isotopic distribution. On the basis of the reaction mechanism shown in Scheme 1 , we could estimate the amounts of $\delta$-aldehyde and $\alpha$-keto acid intermediates from the total amounts of consumption of L-Lys and $\mathrm{P}_{15}$ in $\mathrm{NH}_{3}$. Assuming a quantitative intramolecular condensation into CSB, reduction efficiency of the two kinds of CSB ( $f_{\alpha}$ and $f_{\varepsilon}$ ), defined as yields of ${ }^{15} \mathrm{~N}$ - and ${ }^{14} \mathrm{~N}$-incorporated PCA's based on the amounts of produced $\alpha$-CSB $\left(\mathrm{f}_{\alpha}\right)$ and $\varepsilon$-CSB $\left(\mathrm{f}_{\varepsilon}\right)$, respectively, was determined. The results for Pt-loaded P-25 are shown in Scheme 3. The reaction started with $100 \mu \mathrm{mol}$ of L-Lys, and PCA was produced through the intermediacy of 28 and $23 \mu \mathrm{mol}$ of $\alpha$-CSB and $\varepsilon$-CSB, respectively, as calculated from the consumption of L-Lys (51\%) and $\mathrm{P}_{15}$ in $\mathrm{NH}_{3}$ (45\%). From the amounts of $\alpha-C S B$ and $\varepsilon-C S B, \mathrm{P}_{15}$ in PCA (46\%), and total yield of PCA (34\%), $\mathrm{f}_{\alpha}$ and $\mathrm{f}_{\varepsilon}$ were calculated to be 57 and $78 \%$, respectively. Similarly calculated $\mathrm{f}_{\alpha}$ and $\mathrm{f}_{\varepsilon}$ for specific metal-loaded $\mathrm{TiO}_{2}$ powders are given in Table 1.

As expected from the above results and discussion, $\mathrm{f}_{\alpha}$ and $\mathrm{f}_{\varepsilon}$ varied depending on the kind of photocatalyst. It seems that $\mathrm{f}_{\varepsilon}$ showed a more marked dependence than did $\mathrm{f}_{\alpha}$, and the dependence was closely related to the photocatalytic performance. As for the results of photocatalytic reaction in which $\mathrm{S}_{\mathrm{PCA}}$ is relatively low, e.g., by Pd-loaded $\mathrm{HyCOM} \mathrm{TiO}_{2}$, favoring the reduction of $\alpha$-CSB gave higher $\mathrm{OP}_{\mathrm{PCA}}$ as well as a higher yield of $\mathrm{H}_{2}$. This trend is consistent with the proposed mechanism of a relatively large part of $\varepsilon$-CSB remaining unreduced and production of a by-product of $\mathrm{H}_{2}$ preferably proceeding instead of the reduction of CSB's, especially $\varepsilon$-CSB, by photoexcited electrons. On the other hand, at higher $\mathrm{S}_{\mathrm{PCA}}$, e.g., by Rh-loaded P-25, both CSB's were reduced nonselectively, and $\mathrm{OP}_{\mathrm{PCA}}$ thereby became lower than that of Pd-loaded HyCOM $\mathrm{TiO}_{2}$. Thus, $\mathrm{OP}_{\mathrm{PCA}}$ is governed mainly by the selectivity in the oxidation stage. Relatively high $\mathrm{S}_{\mathrm{PCA}}$ was achieved by Ptloaded P-25 and HyCOM TiO 2 . For these metal-loaded photocatalysts, the reduction of both $\varepsilon$-CSB and $\alpha$-CSB proceeds efficiently, leading to much lower $\mathrm{OP}_{\mathrm{PCA}}$. Accordingly, the general relation between $\mathrm{S}_{\mathrm{PCA}}$ and $\mathrm{OP}_{\mathrm{PCA}}$ on several metal-loaded $\mathrm{TiO}_{2}$ powders, as shown in Fig. 2, could be explained on the basis of the redox-combined mechanism of PCA production. 
Thus, the stereoselectivity of the final product, PCA, is determined by the kind of metal that works as a catalyst for the reduction of CSB intermediates. It is reasonable to expect that reduction of $\alpha$-CSB is easier than that of $\varepsilon$-CSB due to the steric hindrance by the carboxyl group. The catalytic ability of Pd, which gave a relatively low $\mathrm{f}_{\varepsilon}$, is thought to be lower that of Pt or Rh; it is well known that Pt acts as an efficient catalyst for reduction of protons or some organic compounds in deaerated aqueous $\mathrm{TiO}_{2}$ photocatalytic systems, but there have been few reports on Pd-loaded samples. Actually, we have observed much lower photocatalytic activity on Pd-loaded $\mathrm{TiO}_{2}$ powders in $\mathrm{H}_{2}$ production from deaerated aqueous methanol solution (data not shown). Thus, high selectivity of $\alpha$-CSB reduction by Pd-loaded samples might be due to both the structural differences between two types of CSB and the insufficient catalytic ability of Pd to induce $\varepsilon$-CSB reduction. Pt and Rh have sufficient ability for CSB reduction, and this ability was enhanced by loading onto P-25 and $\mathrm{HyCOM} \mathrm{TiO}_{2}$ powders of relatively large surface area to induce high dispersion. Studies on structural characterization of loaded metals correlating with photocatalytic activity, especially for effective control of stereoselectivity, are now in progress.

\section{CONCLUSIONS}

A detailed study on the effects of loading of various metals on the photocatalytic activity of $\mathrm{TiO}_{2}$ powders for PCA synthesis from L-Lys was conducted. The selectivity for oxidation of two kinds of amino groups in L-Lys and reduction of two kinds of cyclic Schiff base intermediates were found to be important factors for stereoselective production of optically active PCA. From the analyses of distribution of ${ }^{15} \mathrm{~N}$-incorporated products using $\alpha-{ }^{15} \mathrm{~N}$-L-Lys as a substrate, it was found for the first time that the selectivity in the reduction stage can be controlled by appropriate metal loading, but the effect on selectivity in the oxidation stage was negligible, i.e., just loading of noble metals as reduction sites is not sufficient to obtain a $\mathrm{TiO}_{2}$ photocatalyst having both high $\mathrm{OP}_{\mathrm{PCA}}$ and $\mathrm{S}_{\mathrm{PCA}}$ simultaneously. Consequently, in order to achieve optimum photocatalytic activity, i.e., 
selective production of optical pure L-PCA with high selectivity, other strategies for further control in the oxidation stage, e.g., modification of the manner of adsorption of $\mathrm{L}$-Lys on $\mathrm{TiO}_{2}$ to change the physicochemical properties of $\mathrm{TiO}_{2}$ surface, is needed.

\section{ACKNOWLEDGEMENTS}

Mr. Tetsuzo Habu and Mr. Kazuhito Matsudaira (Catalysis Research Center, Hokkaido University) are acknowledged for their assistance in the construction of the photoirradiation apparatuses. This work was partly supported by Grants-in-Aid for Scientific Research (Nos. 12874083, 14044003, and 14050007) from the Ministry of Education, Culture, Sports, Science and Technology, Japan.

\section{SCHEME AND FIGURE CAPTIONS}

SCHEME 1. Proposed mechanism of the photocatalytic N-cyclization of L-Lys on platinized $\mathrm{TiO}_{2}$ powders.

SCHEME 2. Schematic procedure for conversion of ammonia with benzaldehyde into benzylamine (BA) using metal-loaded $\mathrm{TiO}_{2}$ particles as hydrogenation catalysts.

SCHEME 3. An example of determination of the efficiency of reduction of two types of CSB on various metal-loaded $\mathrm{TiO}_{2}$ powders.

FIG. 1. Rate ( $\left.\mathrm{r}_{\mathrm{PCA}}\right)$, selectivity $\left(\mathrm{S}_{\mathrm{PCA}}\right)$ and optical purity $\left(\mathrm{OP}_{\mathrm{PCA}}\right)$ of photocatalytic N-cyclization of L-Lys into PCA on metal-loaded P-25 (circles), ST-01 (triangles), and $\mathrm{HyCOM} \mathrm{TiO}_{2}$ (squares). Open, half-filled, and filled symbols denote Pt-, Rh-, and Pd-loaded samples, respectively.

FIG. 2. Correlation between optical purity and selectivity of various metal-loaded catalysts. The symbols are the same as those in Fig.1. 
FIG. 3. GC-MS patterns of TMS derivatives of PCA (upper) obtained from L-Lys (a) or from $\alpha-{ }^{15} \mathrm{~N}-\mathrm{PCA}\left(\mathrm{a}^{\prime}\right)$ and of BA (lower) obtained from L-Lys (b) or from $\alpha-{ }^{15} \mathrm{~N}-\mathrm{PCA}$ (b'). 


\section{REFERENCES}

1. P. D. Bailey, P. A. Millwood and P. D. Smith, Chem. Commun., 633 (1998).

2. B. T. A. Ekenstam and C. Bovin, 4695576 A 870922, U. S. Patent (1987)

3. T. Fujii and M. Miyoshi, Bull. Chem. Soc. Jpn., 48, 1341 (1975).

4. K. Miyazaki, A. Yasutake, H. Aoyagi and N. Izumiya, Mem. Fac. Sci., Kyushu Univ., 12, 165 (1980).

5. M. T. Beck, A. Katho and L. Dozsa, Inorg. Chim. Acta, 55, L55 (1981).

6. B. Ohtani, S. Tsuru, S.-i. Nishimoto, T. Kagiya and K. Izawa, J. Org. Chem., 55, 5551 (1990).

7. B. Ohtani, K. Iwai, H. Kominami, T. Matsuura, Y. Kera and S.-i. Nishimoto, Chem. Phys. Lett., 242, 315 (1995).

8. P. V. Kamat, Chem. Rev., 93, 267 (1993).

9. M. A. Fox and M. T. Dulay, Chem. Rev., 93, 341 (1993).

10. T. Hirakawa, H. Kominami, B. Ohtani and Y. Nosaka, J. Phys. Chem. B, 105, 6993 (2001).

11. P. Pichat, C. Guillard, C. Maillard, L. Amalric and J. C. D'Oliveira, Trace Met. Environ., 3, 207 (1993).

12. R. I. Bickley, R. K. M. Jayanty, V. Vishwanathan and J. A. Navio, NATO ASI Ser., Ser. C, 174, 555 (1986).

13. M. R. Hoffmann, S. T. Martin, W. Choi and D. W. Bahnemann, Chem. Rev., 95, 69 (1995).

14. A. Fujishima, K. Hashimoto and T. Watanabe, $\mathrm{TiO}_{2}$ Photocatalysis-Fundamentals and Applications, BKC, Tokyo, 176 (1999).

15. M. A. Fox and M. J. Chen, J. Am. Chem. Soc., 105, 4497 (1983).

16. T. Ohno, K. Nakabeya and M. Matsumura, J. Catal., 76, 176 (1998).

17. T. Ohno, T. Kigoshi, K. Nakabeya and M. Matsumura, Chem. Lett., 877 (1998).

18. B. Ohtani and T. Ohno, in Photocatalysis -Science and Technology-, eds. M. Kaneko and I. Okura, Kodansha-Springer, Tokyo, p. in press (2002).

19. F. Mahdavi, T. C. Bruton and Y. Li, J. Org. Chem., 58, 744 (1993).

20. K. H. Park, H. S. Joo, K. I. Ahn and K. Jun, Tetrahedron Lett., 36, 5943 (1995).

21. B. Ohtani, Y. Goto, S.-i. Nishimoto and T. Inui, J. Chem. Soc., Faraday Trans., 92, 4291 
(1996).

22. S.-i. Nishimoto, B. Ohtani, T. Yoshikawa and T. Kagiya, J. Am. Chem. Soc., 105, 7180 (1983).

23. B. Ohtani, H. Osaki, S.-i. Nishimoto and T. Kagiya, Tetrahedron Lett., 27, 2019 (1986).

24. K. Shibata, T. Mimura, M. Matsui, T. Sugiura and H. Minoura, J. Chem. Soc., Chem. Commun., 1318 (1988).

25. H. Minoura, Y. Katoh, T. Sugiura, Y. Ueno, M. Matsui and K. Shibata, Chem. Phys. Lett., 173, 220 (1990).

26. K. Shibata, A. Hida, M. Matsui, H. Muramatsu, T. Sugiura and H. Minoura, Conference on Recent Development of Photocatalytic Reaction, Tokyo, 24 (1994).

27. H. Kisch and W. Lindner, Chemie in Unserer Zeit, 35, 250 (2001).

28. A. Reinheimer, R. van Eldik and H. Kisch, J. Phys. Chem. B, 104, 1014 (2000).

29. H. Keck, W. Schindler, F. Knoch and H. Kisch, Chemistry-a European Journal, 3, 1638 (1997).

30. B. Ohtani, T. Yako, Y. Samukawa, S.-i. Nishimoto and K. Kanamura, Chem. Lett., 91 (1997).

31. H. Kominami, T. Matsuura, K. Iwai, B. Ohtani, S.-i. Nishimoto and Y. Kera, Chem. Lett., 693 (1995).

32. H. Kominami, S. Murakami, Y. Kera and B. Ohtani, Catal. Lett., 56, 125 (1998).

33. B. Ohtani, J.-i. Kawaguchi, M. Kozawa, Y. Nakaoka, Y. Nosaka and S.-i. Nishimoto, J. Photochem. Photobiol., A: Chem., 90, 75 (1995).

34. B. Ohtani, J.-i. Kawaguchi, M. Kozawa, S.-i. Nishimoto, T. Inui and K. Izawa, J. Chem. Soc., Faraday Trans., 91, 1103 (1995).

35. H. Kominami, J.-i. Kato, M. Kohno, Y. Kera and B. Ohtani, Chem. Lett., 1051 (1996). 


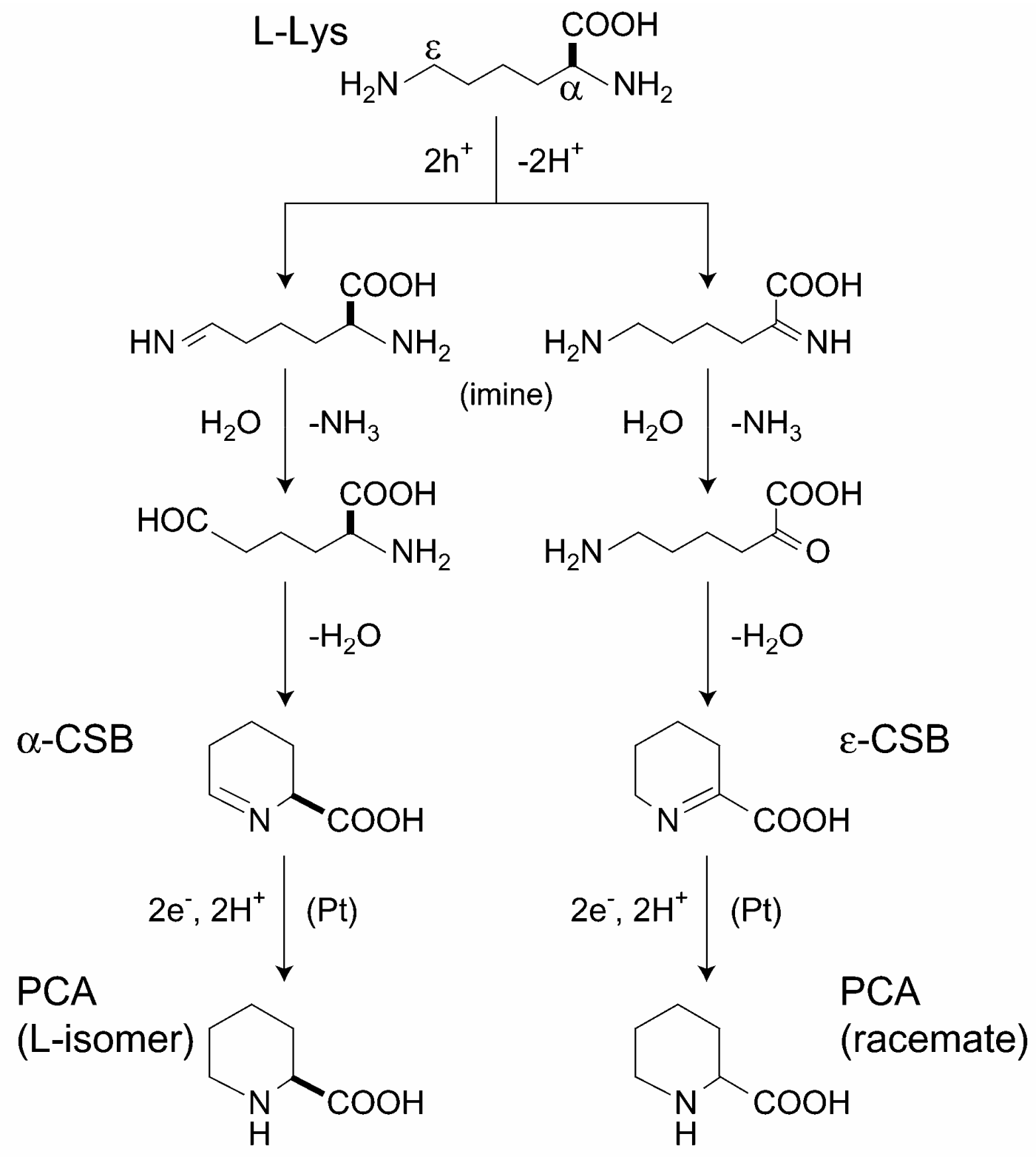

SCHEME 1. Proposed mechanism of the photocatalytic N-cyclization of L-Lys on platinaized $\mathrm{TiO}_{2}$ powders. 
$\mathrm{NH}_{3}+\underset{-\mathrm{H}_{2} \mathrm{O}}{\longrightarrow} \stackrel{\mathrm{C}=\mathrm{O}}{\longrightarrow} \stackrel{\mathrm{Rh}, \mathrm{Pd}, \mathrm{Pt})}{\longrightarrow}$

SCHEME 2. Schematic procedure for conversion of ammonia with benzaldehyde into benzylamine (BA) using metalloaded $\mathrm{TiO}_{2}$ particles as hydrogenation catalysts. 


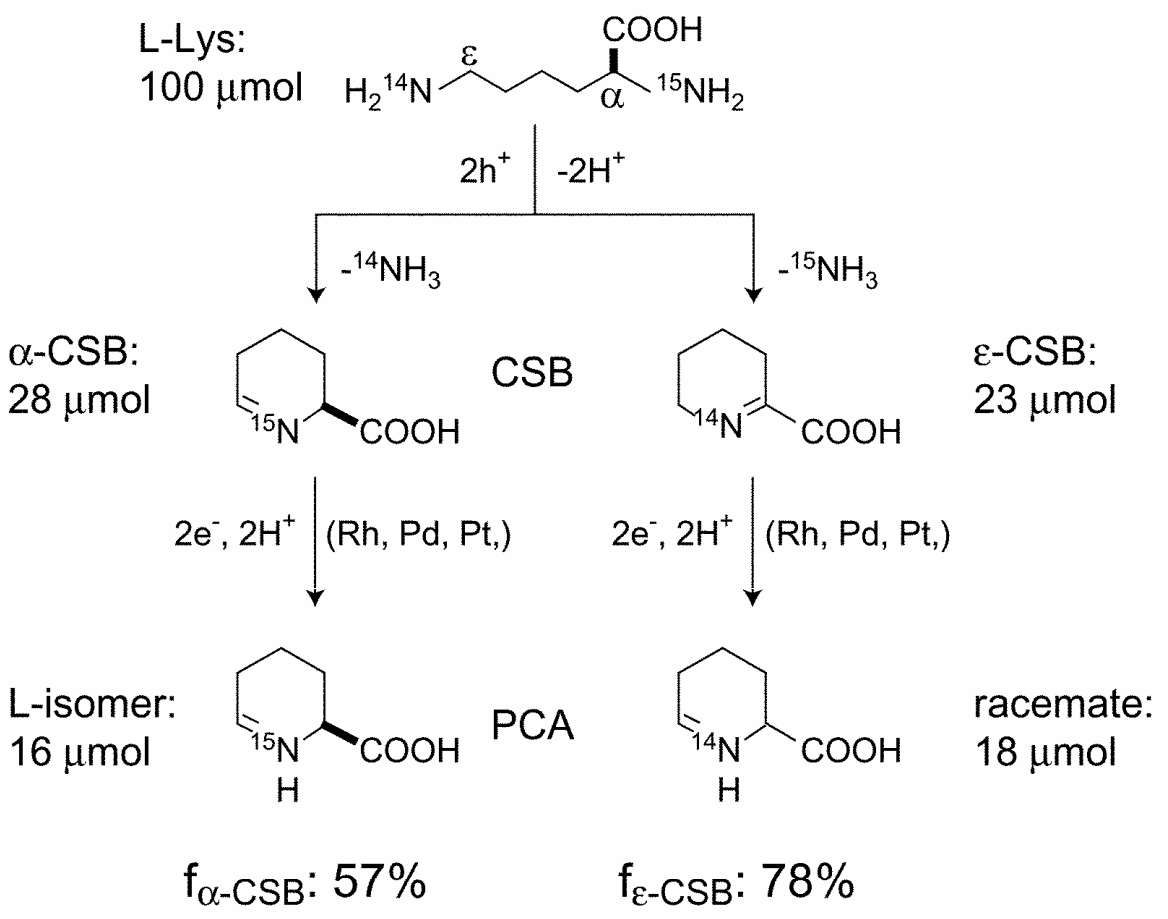

SCHEME 3. An example of determination of the efficiency of reduction of two types of $\mathrm{CSB}$ on various metal loaded $\mathrm{TiO}_{2}$ powders. 


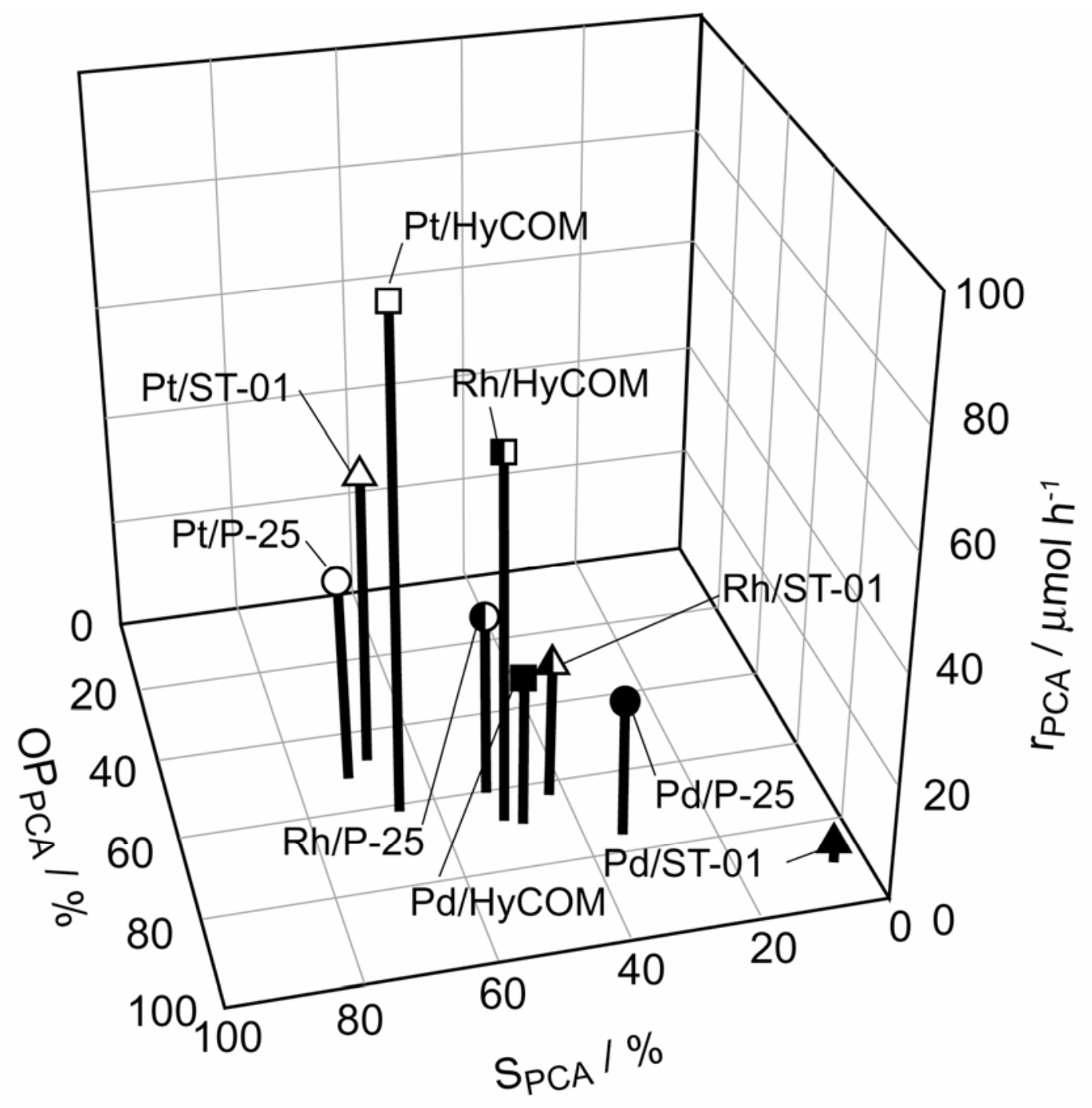

FIG. 1. Rate $\left(\mathrm{r}_{\mathrm{PCA}}\right)$, selectivity $\left(\mathrm{S}_{\mathrm{PCA}}\right)$ and optical purity $\left(\mathrm{OP}_{\mathrm{PCA}}\right)$ of photocatalytic N-cyclyzation of L-Lys into PCA on metalloaded P-25 (circles), ST-01 (triangles), and $\mathrm{HyCOM} \mathrm{TiO}_{2}$ (squires). Open, half-filled, and filled symbols denote Pt-, Rh-, and Pd-loaded samples, respectively. 


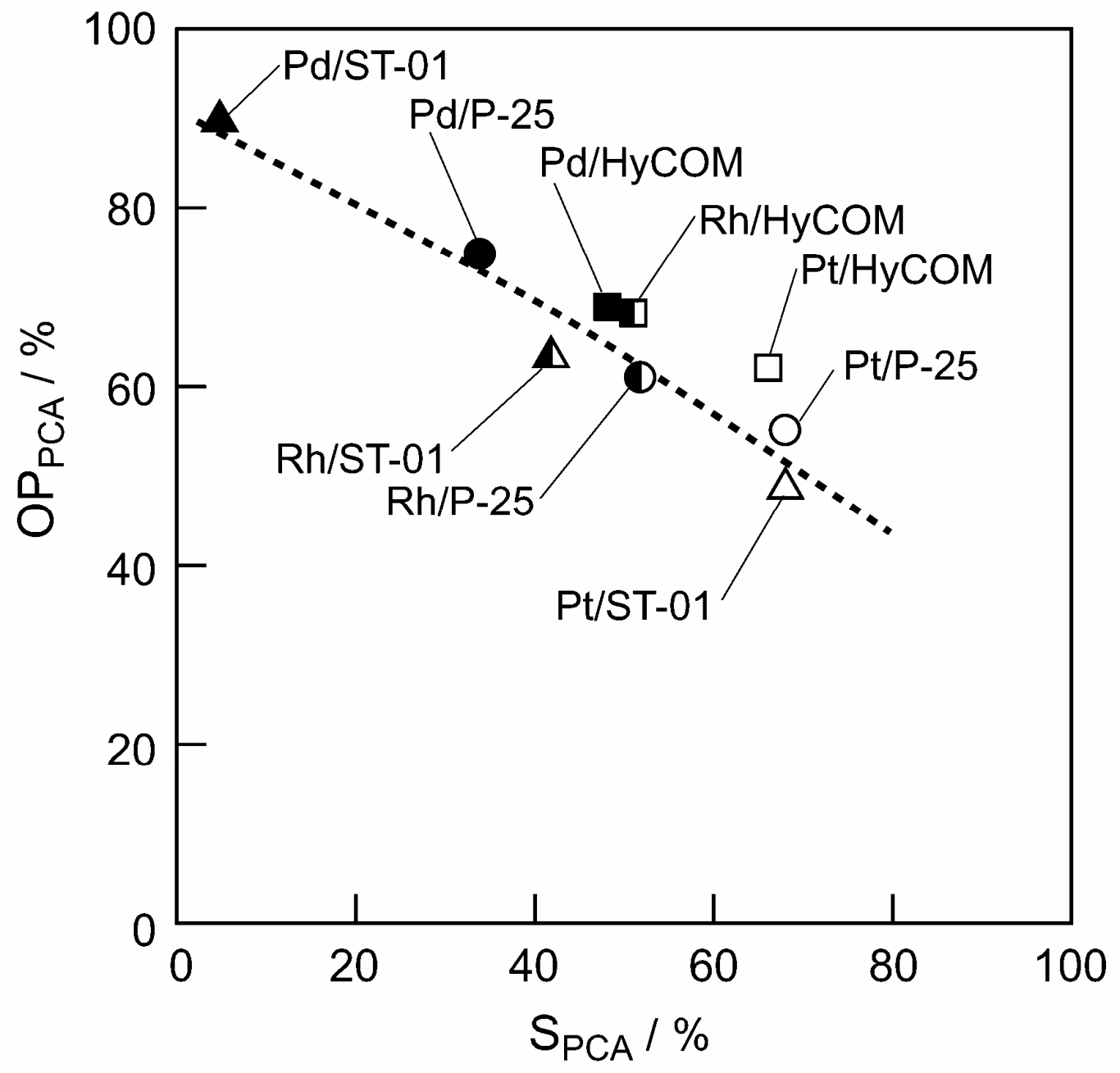

FIG. 2. Correlation between optical purity and selectivity of various metal loaded catalysts. The symbols are the same as those in Fig.1. 


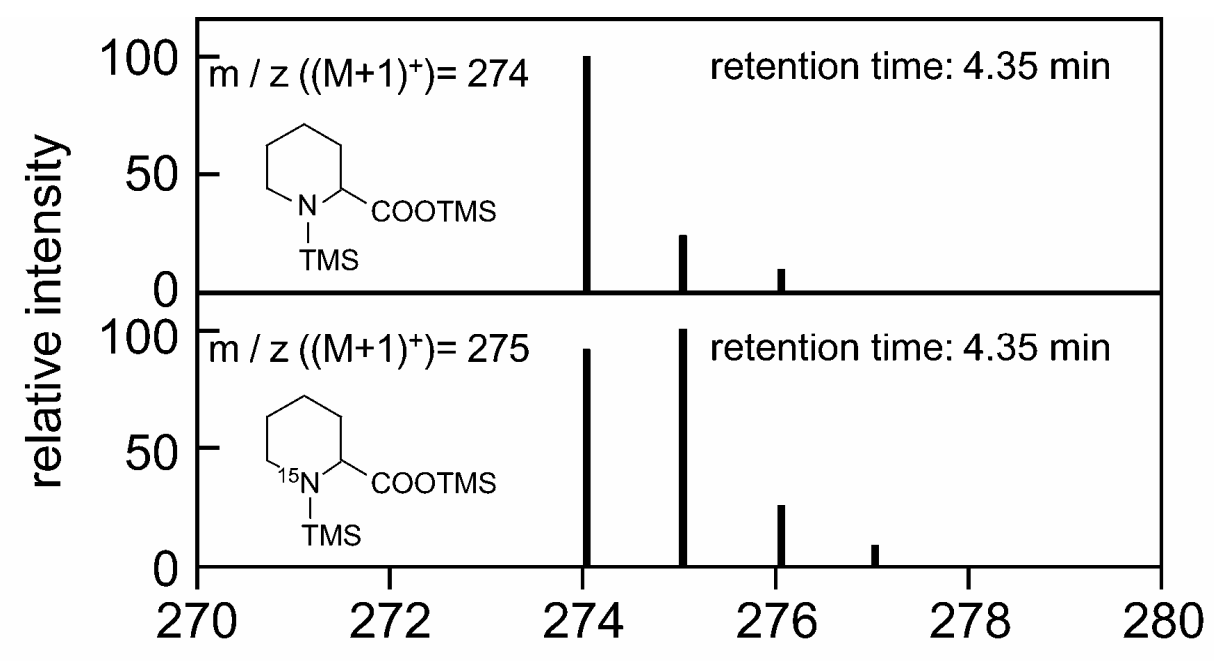

$\mathrm{m} / \mathrm{z}$

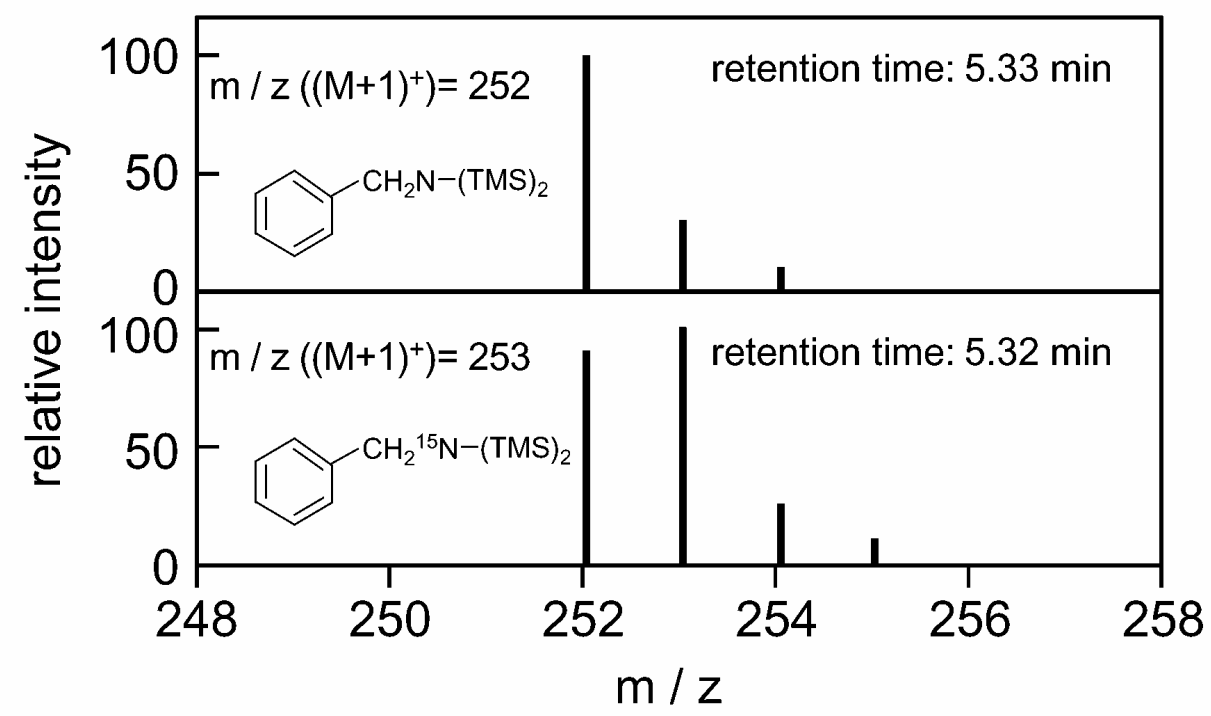

FIG. 3. GC-MS patterns of TMS derivatives of PCA (upper) obtained from L-Lys (a) or from $\alpha-15 \mathrm{~N}-\mathrm{PCA}\left(\mathrm{a}^{\prime}\right)$, and BA (lower), obtained from L-Lys (b) or from $\alpha-15 N-P C A\left(b^{\prime}\right)$. 


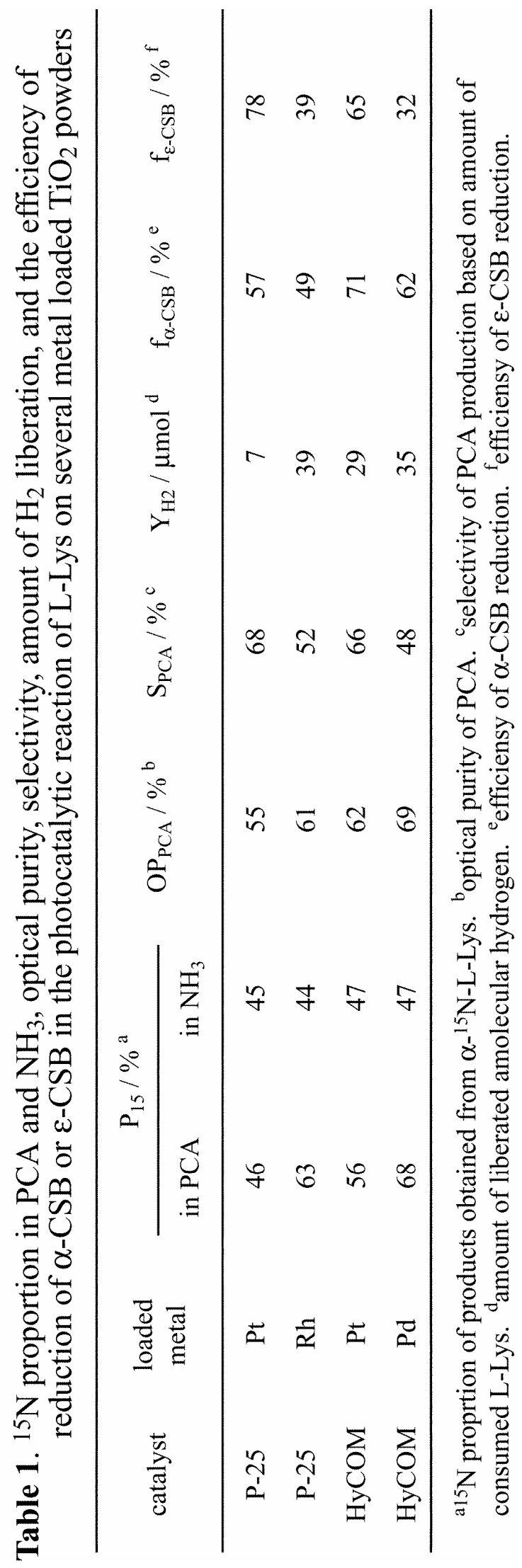


